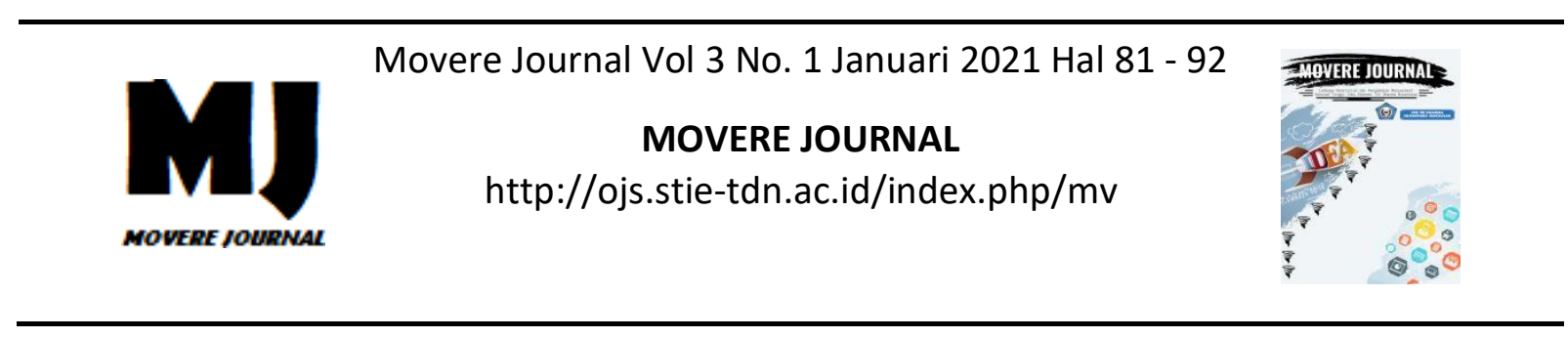

\title{
PENGARUH STRATEGI PROMOSI TERHADAP PENINGKATAN KUNJUNGAN WISATAWAN DI KOTA PALOPO
}

\author{
${ }^{1}$ Awaluddin, ${ }^{2}$ Sumarni S, \\ ${ }^{1}$ Sekolah Tinggi Ilmu Ekonomi Wira Bhakti Makassar, ${ }^{2}$ Sekolah Tinggi Ilmu Ekonomi Wira Bhakti \\ Makassar, \\ Email : ${ }^{1}$ awal@wirabhaktimakassar.ac.id, ${ }^{2}$ sumarnisarong@wirabhaktimakassar.ac.id
}

\begin{abstract}
Abstrak: Tujuan penelitian ini adalah untuk mengetahui pengaruh strategi promosi terhadap peningkatan kunjungan wisatawan di Kota Palopo. Populasi pada penelitian ini merupakan semua pengunjung atau wisatawan yang berkunjung pada wisata alam yaitu wisata Kambo Higland dan Pantai Labombo dari tanggal 09 Juni 2020 hingga 09 Agustus 2020 di Kota Palopo. Jumlah kunjungan wisata adalah sebanyak 106.211 orang. Sampel sebanyak 100 responden dengan menggunakan rumus Slovin. Penelitian ini merupakan penelitian kuantitatif dengan pendekatan deskriptif). Teknik pengujian yang dipakai yaitu uji validitas dengan menggunakan penganalisaan (OLS) regeresi linear sederhana dan uji t digunakan untuk menguji hipotesis. Hasil penelitian menunjukkan bahwa (1) mayoritas responden yang berkunjung ke Kota Palopo adalah perempuan dengan proporsi $55 \%$, dan mayoritas usia responden adalah 17-26 tahun dengan proporsi 41\% (2) variabel promosi dengan indicator Publisitas, Press Releace (Jumpa Pers), News (Pesan/Berita), Event (acara), Penggunaan Media Baru berpengaruh terhadap peningkatan kunjungan wisatawan di Kota Palopo.
\end{abstract}

Kata Kunci : Strategi Promosi, Peningkatan kunjungan wisatawan

\begin{abstract}
The purpose of this study was to determine the effect of promotional strategies on increasing tourist visits in Palopo City. The population in this study were all visitors or tourists visiting natural tourism, namely Kambo Higland tourism and Labombo Beach from 09 June 2020 to 09 August 2020 in Palopo City. The number of tourist visits was 106,211 people. A sample of 100 respondents using the Slovin formula. This research is a quantitative research with a descriptive approach). The testing technique used is the validity test using simple linear regression analysis (OLS) and the t test is used to test the hypothesis. The results showed that (1) the majority of respondents who visited Palopo City were women with a proportion of 55\%, and the majority of respondents' ages were 17-26 years old with a proportion of $41 \%$ (2) promotional variables with indicators of Publicity, Press Releace (Press Releace), News (Message / News), Event (event), Use of New Media has an effect on increasing tourist visits in Palopo City.
\end{abstract}

Keywords : Promotion Strategy, Increased tourist visits 


\section{A. PENDAHULUAN}

Palopo merupakan wilayah yang letaknya diujung utara Provinsi Sulawesi Selatan jaraknya $362 \mathrm{~km}$ dari Makassar. Kota yang berjuluk kota IDAMAN (Indah, Damai, Aman) telah berapa kali mengantongi penghargaan bergengsi di bidang kebersihan, salah satunya yaitu Piala Adipura. Selain itu Kota Palopo juga menyimpan potensi wisata yang sangat luar biasa. Tiga jenis wisata yaitu wisata alam, wisata buatan dan wisata sejarah budaya. Objek wisata alam terdiri dari : Pantai Labombo, Air Terjun Latuppa, Kambo Higland, dan Permandian Alam Batu Papan. wisata buatan terdiri dari : Waterboom Agro Wisata, Taman Kirab dan wisata sejarah budaya terdiri dari : Masjid Jami Tua Palopo, Gua Kallo Dewata. Jumlah kunjungan wisatawan di Kota Palopo selama 5 tahun terakhir mengalami fluktiasi ini ditunjukkan pada tahun 2014 sebanyak 86,955 wisatawan, tahun 2015 mengalami kenaikan 110,078 wisatawan, sedangkan pada tahun 2016 mengalami penurunan 95,918 wisatawan, tahun 2017 mengalami kenaikan 99,517 wisatawan, dan pada tahun 2018 mengalami kenaikan 106,211. Data yang masih berfluktuasi tersebut diperlukan strategi yang tepat agar wisatawan yang berkunjung terus meningkat dari tahun ke tahun. Strategi tersebut bisa dalam bentuk strategi promosi untuk menyukseskan sektor pariwisata, peranan promosi pariwisata adalah sesuatu yang sangat krusial. Agar tingkat kunjungan wisata meningkatkan maka pengelola suatu kawasan obyek wisata perlu melakukan kegiatan promosi (Lesmana, I. S., Bahits, A., \& Tabrani, M. B. ,2020

Promosi merupakan usaha untuk memperbesar daya tarik objek wisata serta menginformasikan objek-objek dan atraksi wisata yang ada kepada calon-calon wisatawan. Promosi yang gencar diharapkanakan merangsang kunjungan wisatawan. Promosi diawali dengan komunikasi persuasi untuk membangkitkan perhatian dan pada akhirnya berlanjut menjadi minat untuk berkunjung. Bentuk promosi bukan hanya tourism map, guidebook, brosur, leaflet, internet namun juga termasuk penyelenggaraan eventevent, pameran, serta penampilan atraksi seni budaya (Areks \& Nadjib, 2015). Bauran promosi seperti periklanan, promosi penjualan, hubungan masyarakat dalam penelitian ini berpengaruh pada minat pengunjung wisata budaya pesta adat Erau (Indriastuty, N. 2020)

\section{B. TELAAH LITERATUR DAN PENGEMBANGAN HIPOTESIS}

\section{Pengertian Promosi Pariwisata}

Aktivitas dengan cakupan pendistribusian pengenalan materi, contohnya pada film, iklan, atau keberagamannya, seperti televisi, majalah bioskop dan lainnya dengan pemenuhan yang menjadi persyaratan keseluruhannya. Pemenuhan yang paling rendah, yaitu dikarenakan banyaknya dana, kondisi yang stabil, uang bom mempunyai waktu untuk pergi, pada perjalanannya, kesuatu arah, dengan tujuannya menstransfer info yang diperoleh dan dampak dari orang yang akan menikmati kota tempat dia melakukan kunjungan.

Maknanya disini ialah sebuah propaganda, yang berdasar pada perencanaan teraturan dengan kontinu. Penunjukannya pada orang didalam sebuah wilayah sendiri, dengan maksud pada pengunggahan arah pikiran agar terciptanya rasa sadar pada perolehan pendukungan. Pengenalan juga dimaksudkan dengan diterangkannya yang mempunyai kandungan sarana yang punya ketertarikan pada penyajiannya ke pengunjung (dalam pendit 1999:23). Hal tersebut di klarifikasikan pada dua 
pembagian:

a. Promosi Langsung

Target terakhir dari sebuah akitvitas dipasarkannya atau pengenalan pada personalitas, dengan dikeluarkannya finansial pengadaan perjalanan wisata, kesuksesannya bisa terlihat dari penjumlahan yang benar-benar ingin melakukan transaksi makin baik.

b. Promosi Tidak Langsung

Hal tersebut ditunjukan pada penyaluran barang pada pengunjuk, jasa perjalaan dan keberagamannya, agen dan lainnya.

\section{Strategi Promosi Pariwisata}

Pengertian strategi menurut Stoner, Freeman,dan Gilbert dalam (mayasari, 2014 :10) diartikan dua perspektif :

a. Dengan apa yang ingin dilaksanakan, maknanya pada penentuan ataupun pencapaian dari sebuah organisasi dan penerapannya.

b. Pelaksanaanya, dengan apa yang dilakukan menanggapi sekitarnya.

"Strategi merupakan perencanaan maupun penindakan dengan memakai daya mampu yang mereka punyai pada penargetannya.". (mayasari, 2014:10). Promosi ialah variabel yang krusial pada pelaksanaannya oleh sebuah organisasi, dengan pemasaran produk, aktivitas yang gunanya pada penghubung diantara sebuah organisasi dengan pemakainya, media mempengaruhi pembeli pada aktivitas pengguna, dengan yang dibutuhkan. Dilaksanakan dengan memakai media pengenalan (Lupiyoadi, 2013:178).

Promosi ialah variabel terkhusus yang mempuyai ketetarikan pada Objek Wisata, bermacam-macam, dikelolah pariwisata. Merupakan cara komunikasi, menginformasikan pembujukan dan pengingat pengunjukan mengenai keungglan objek wisata ditawarkan kepada calon wisatawan tentang produk yang ditawarkan melakukan wisata ke objek tersebut dengan waktu dan tempat yang tepat. Menurut Gromang dalam (Novalina, 2013:20) Promosi wisata beranjak dari prediksi dan kaitannya denga upaya yang mengacu dengan dimungkinkannya daya jual, contohnya pada keseluruhan aktivitas yang terencana, pengenalan melalu pengiklanana, film, panduan pemakaian dan lainnya.

Promosi wisata merupakan komunikasi dalam pemasaran pariwisata. Dalam satu objek wisata atau destinasi wisata, promosi wajib dilakukan secara baik dan berkesinambungan. Promosi pariwisata guna pemberitahuan, pembujukan dan peningkatan daya beli, dengan keinginan kunjungan yang dipromosikan. Promosi dilaksanakan dengan sarana yang baik, pada peningkatan akitvitas.

\section{Pengertian Pariwisata dan Wisatawan}

\section{Pariwisata}

Pengertian Pariwisata Menurut Para Ahli :

a. Menurut James J. Splilance pariwisata merupakan hal yang ditempuh dari satu ketempat lainnya, sifatnya tidak tetap sebagain upaya menyeimbangkan ataupun keselarasan.

b. Menurut MC. Intosh dan Goelder pariwisata adalah hal yang menjadi penarik, berbagai komoditas yang diperlukan atau yang menjadi peminatan.

c. Menurut Gluckman keseluruhan relasi sementara dngan yang ada 


\section{Wisatawan}

ditempat tersebut.

Defenisi yang jelas, dengan anggapan pada pelaksanaan yang menjadi kategorinya (The Dictionary of Touriesm 1981). Menurut rumusan Internasional Union Of Offical Travel Organization (IUOTO) dalam (Akrom, 2014:26) pada tahun 1963 subjek wisata atau pelaku perjalanan yang menjadi pembeda terdiri dari dua makna, yaitu:

a. Wisatawan merupakan orang yang melakukan kunjungan dari 24 jam, dengan penggolongan :

- Pesiar adalah untuk rekreasi, liburan, independen, studi dan olahraga.

- Hubungan dagang, sanak saudara, konferensi dan misi.

b. Pelancong merupakan orang yang melakukan kunjunagn kurang dari 24 jam, dengan penggolongan:

- Domestik tourism yang muncul pada orang yang memiliki tempat menatap dinegara tersebut.

- Inbound Tourism yang menjadi pengunjung, asalnya bukan dari daerah tersebut.

- Outbound tourism merupakan sebuah kunjungan ke negara lainnya.

- Internal tourism ialah penggabungan dari domestic.

- Internasional tourism merupakan penggabungan dai inbpund dan outbound tourism.

Hal yang terkait pada teori atau sebuah konsep yang menjadi penarik dari pengkajian yang dilaksanakan dan dipakai menjadi acuan penyusunan, ini merupakan skema yang menggambarkan korelasi independ yang mempunyai keterlibatan hubungan dan konsep yang menjadi permasalahan yang akan melakuakn penelitian.

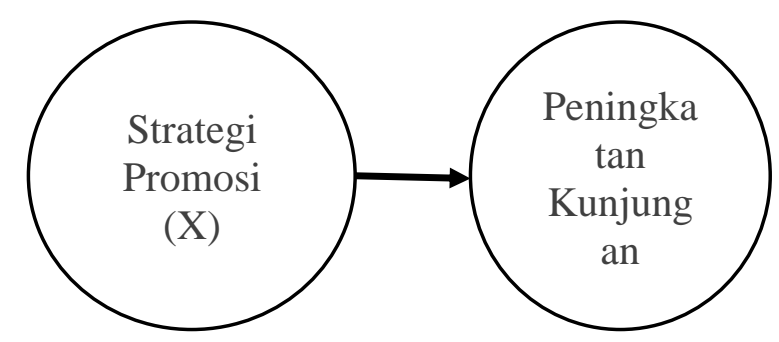

Gambar 1 Kerangka konseptual

Terdapat dua independ dimana independ bebas/independent yaitu Strategi Promosi disimbolkan dengan (X) dan memiliki 5 indikator yaitu : Publisitas,Press Releace (Jumpa Pers), News (Pesan/Berita), Event (acara), Penggunaan Media Baru dan dikutip oleh Nova (2011:54). Sedangkan varibel terikat/dependen yaitu Peningkatan Kunjungan Wisatawan disimbolkan dengan (Y) dan memiliki 5 indikator yaitu : Wisatawan, Pengangkutan, Daya Tarik Wisata, Fasilitas Pelayanan, dan Informasi/Promosi dan dikutip oleh Yanti (2012:69).

\section{METODE PENELITIAN}

Jenis pengkajian yang dipakai yaitu penelitian kuantitatif dengan pendekatan deskriptif. Lokasi penelitian ini bertempat pada Dinas Pariwisata dan Ekonomi Kreatif Kota Palopo yang beralamat di Jln Balaikota No 1 Kota Palopo. Jangka waktu penelitian ini dilaksanakan dalam waktu dua bulan, yaitu dimulai pada tanggal 09 Juni 2020 sampai dengan 09 Agustus 2020. Populasi dan sampel. Populasi pada penelitian ini merupakan semua pengunjung atau wisatawan yang berkunjung pada wisata alam yaitu wisata Kambo Higland dan Pantai Labombo Teknik 
Sampel dengan carai Proposive Sampling yang disebut pula dengan judgement sampling, dengan mengambil sampel berdasarkan penimbang dari kelompok (Sanusi 2011:95). dalam pengambilan sampel yaitu : merupakan wisatawan yang berkunjung ke kota Palopo, berusia antara 17 - 50 dengan edukasi dan perespon yang buta huruf, dengan pengisian kuesioner. Pada penentuan sampel yang diperlukan pada pengkajian ini dengan rumus slovin, memakai rumus pengamsumsian dengan tingkatan hal yang salah $5 \%$ (Umar, 2002:127). penjumlahan yang akan dijadikan perespon dalam pengkajian ini sebanyak 369 responden, dengan hal yang menjadi penimbangnya, batas waktu, umur, usia dan estimasi pembiayaan yang dipakai 100 responden.

Pengukuran variabel yang dilakukan pada penilaian ini memakai skala likert. Skala Likert dipakai menjadi tolak ukur penyikapan, respon dan pengelompokan peristiwa (sugiyono 2012:136). Pengukurannya dengan penjabaran indikator variabel, yang menjadi pemusatan serta disusunnya item yang menjadi pernyataan.

Jawaban setiap instrumen dari Skala Likert mempunyai gradasi dari sangat positif sampai sangat negatif yang berupa kata-kata seperti Sangat tidak baik, kurang baik, cukup baik, cukup, baik dan sangat baik dengan skor 1 sampai 5. Pengujian hipotesa yang diajukan pada pengkajian dengan memakai metode penganalisaan OLS (Ordinary Lesast Square), analisis regresi linear sederhana..

\section{HASIL DAN PEMBAHASAN HASIL}

\section{Analisis Deskriptif}

Ditunjukan untuk pengetahuan mean, yang merespon variabel, dengan dihitung memakai bantuan Exel, dengan yang dimaksudkan kedalam pengelompokan interval, kelompok interval dimana kelompok interval tersebut telah dihitung berdasarkan bobot skala likert:

$$
\left(\frac{\text { Nilai Maksimum }- \text { Nilai Minimum }}{\text { Kelas Interval }}=\frac{5-1}{5}=0,8\right)
$$

dengan demikian didapat skor 1,00-1,79 termasuk kategori sangat tidak baik, 1,80-2,59 termasuk kategori kurang baik, 2,60-3,39 termasuk kategori cukup baik, 3,404,19 termasuk kategori baik dan 4,205,00 termasuk kategori sangat baik. Hasil analisa deskriptif variable adalah sebagai berikut :

\section{Tabel 1}

Hasil Analisis Deskriptif Variabel

\begin{tabular}{|c|c|c|c|c|c|}
\hline variabel & butir & Mean & Kategori & $\begin{array}{l}\text { Total } \\
\text { Mean }\end{array}$ & keterangan \\
\hline \multirow{3}{*}{$\begin{array}{l}\text { Strategi } \\
\text { Promosi }(\mathrm{X})\end{array}$} & $\mathrm{P} 1$ & 4,47 & $\begin{array}{l}\text { Sangat } \\
\text { baik }\end{array}$ & \multirow{3}{*}{4,50} & $\begin{array}{l}\text { Melakukan publikasi yg dilakukan oleh } \\
\text { wartawan lokal dan non lokal }\end{array}$ \\
\hline & $\mathrm{P} 2$ & 4,36 & $\begin{array}{l}\text { Sangat } \\
\text { baik }\end{array}$ & & $\begin{array}{l}\text { pemerintah Kota Palopo melakukan press } \\
\text { releace atau berita untuk surat kabar kepada } \\
\text { media massa }\end{array}$ \\
\hline & P3 & 4,70 & $\begin{array}{l}\text { Sangat } \\
\text { baik }\end{array}$ & & $\begin{array}{l}\text { Pemerintah Kota Palopo menyampaikan pesan } \\
\text { atau berita kepada masyarakat/khalayak }\end{array}$ \\
\hline
\end{tabular}


$\begin{array}{cc}\text { P4 4,64 } & \begin{array}{c}\text { Sangat } \\ \text { Baik }\end{array}\end{array}$

P5 4,33 $\begin{gathered}\text { Sangat } \\ \text { baik }\end{gathered}$
Pemerintah Kota Palopo melakukan even/acara dalam proses penyebaran informasi kepada masyarakat/khalayak

Pemerintah kota Palopo melakukan pemakaian di komunikasi masyarakat dengan memakai sarana internet

\begin{tabular}{|c|c|c|c|c|c|}
\hline \multirow{5}{*}{$\begin{array}{c}\text { Peningkatan } \\
\text { Kunjungan } \\
\text { Wisatawan } \\
\text { (Y) }\end{array}$} & P1 & 4,44 & $\begin{array}{l}\text { Sangat } \\
\text { baik }\end{array}$ & \multirow{5}{*}{4,33} & $\begin{array}{l}\text { Mengetahui krakteristik dengan peminatan } \\
\text { dengan musim pada pelaksanaan perjalanan }\end{array}$ \\
\hline & P2 & 3,33 & $\begin{array}{l}\text { Cukup } \\
\text { baik }\end{array}$ & & $\begin{array}{l}\text { Menyediakan media transfor ke daerah lainnya } \\
\text { yang menjadi tujuan }\end{array}$ \\
\hline & P3 & 4,50 & $\begin{array}{l}\text { Sangat } \\
\text { baik }\end{array}$ & & $\begin{array}{l}\text { Bagaimana daya tarik wisata, apakah sudah } \\
\text { memenuhi syarat berikut apa yang dapat dilihat }\end{array}$ \\
\hline & P4 & 4,71 & $\begin{array}{l}\text { Sangat } \\
\text { Baik }\end{array}$ & & $\begin{array}{l}\text { Bagaimana fasilitas pelayanan, hotel, pelaanan } \\
\text { di kantor yang akan menjadi kunjungan }\end{array}$ \\
\hline & P5 & 4,65 & Baik & & $\begin{array}{l}\text { Dibutuhkan pengenalan pengiklanan yang } \\
\text { dilakukan dengan penyebaran calon untuk } \\
\text { pengambilan putusan }\end{array}$ \\
\hline
\end{tabular}

Sumber : Hasil Pengolahan Data Primer 2020

\section{Uji Validitas dan Reliabilitas}

\section{a. UjiValiditas}

Uji validitas digunakan untuk mengukur ketepatan dalam setiap instrumen dimana instrumen tersebut dapat diketahui valid atau tidaknya. Nilai $r$ hitung dari uji validitas akan dibandingkan dengan r tabel dari kolerasi Product Moment (Person). Dalam uji validitas ini, suatu pernyataan akan valid apabila $r$ hitung > $r$ tabel. Cara menentukan $r$ tabel adalah dengan menggunakan $($ degree of fredoom $)=n-2$, berarti $\mathrm{df}$ $=100-2=98, \mathrm{n}$ adalah jumlah responden. Pengujian validitas dalam penelitian ini menggunakan 100 responden dengan ketentuan $\mathrm{r}$ tabel 98, $\square=5 \%$, maka $\mathrm{r}$ tabel $=$ 0,196 . Adapun uji validitas data adalah sebagai berikut:

Tabel 2 Hasil Uji Validitas Variabel Strategi Promosi (X)

\begin{tabular}{lcccc} 
Variabel & Pernyataan & r(Hitung) & r (Tabel) & Status \\
\hline Strategi & 1 & 0,465 & 0,196 & Valid \\
\hline
\end{tabular}




\begin{tabular}{lcccc}
\hline $\begin{array}{l}\text { Promosi } \\
(\mathrm{X})\end{array}$ & 2 & 0,542 & 0,196 & Valid \\
& 3 & 0,681 & 0,196 & Valid \\
& 4 & 0,780 & 0,196 & Valid \\
& 5 & 0,612 & 0,196 & Valid \\
\hline
\end{tabular}

Sumber : Hasil Pengolahan Data Primer 2020

Dari tabel 2 dapat disimpulkan bahwa setiap pernyataan persepsi wisatawan pada strategi promosi (X) dinyatakan valid, karena semua item memiliki $\mathrm{r}$ hitung lebih besar dari $\mathrm{r}$ tabel. Oleh karena itu tidak perlu ada instrumen yang harus dihilangkan.

Tabel 3 Hasil uji validitas variabel peningkatan kunjungan wisatawan (Y)

\begin{tabular}{lcccc}
\multicolumn{1}{c}{ Variabel } & Pernyataan & r (Hitung) & r (Tabel) & Status \\
\hline $\begin{array}{l}\text { Peningkatan } \\
\text { Kunjungan }\end{array}$ & 1 & 0,687 & 0,196 & Valid \\
$\begin{array}{l}\text { Wisatawan (Y) } \\
2\end{array}$ & 0,543 & 0,196 & Valid \\
& 4 & 0,496 & 0,196 & Valid \\
& 5 & 0,710 & 0,196 & Valid \\
& 5 & 0,718 & 0,196 & Valid \\
\hline
\end{tabular}

Sumber : Hasil Pengolahan Data Primer 2020

Dari tabel 3 dapat disimpulkan bahwa setiap pernyataan persepsi wisatawan pada peningkatan kunjungan wisatawan (Y) dinyatakan valid, karena semua item

Uji reliabilitas digunakan untuk mengukur tingkat ketepatan, ketelitian atau keakuratan sebuah memiliki $\mathrm{r}$ hitung lebih besar dari $\mathrm{r}$ tabel. Oleh karena itu tidak perlu ada instrumen yang harus dihilangkan.

\section{b. Uji Reliabilitas}

instrumen, Ujireliabilitas pada penelitian ini menggunakan teknik analisa Cronbach Alpha. Dalam 
Reability Static akan didapat nilai dari Cronbach Alpha, apabila nilai Cronbach Alpha $\square 0,6$ maka, suatu kesioner tersebut dapat dikatakan reliable. Pengujian reliabilitas pada penelitian ini menggunakan 100 responden. Adapun uji reliabilitas data adalah sebagai berikut :

\section{Tabel 4 Hasil Uji Reabilitas Variabel Strategi Promosi (X)}

\section{Reliability Statistics}

\begin{tabular}{|c|c|}
\hline Cronbach's Alpha & N of Items \\
\hline .607 & 5 \\
\hline
\end{tabular}

Sumber : Hasil Pengelolahan Data Primer 2020

Dari tabel 4 dapat dilihat bahwa setiap pernyataan presepsi wisatawan pada strategi promosi (X) di Kota Palopo dinyatakan reliabel karena memiliki nilai Cronbach Alpha $\geq 0,6$.

Tabel 5 Hasil uji reabilitas variabel peningkatan kunjungan wisatawan (Y) Reliability Statistics

\begin{tabular}{|c|c|}
\hline Cronbach's Alpha & N of Items \\
\hline .610 & 5 \\
\hline
\end{tabular}

Sumber : Hasil Pengelolahan Data Primer 2020

Dari tabel 5 dapat dilihat bahwa setiap pernyataan presepsi wisatawan pada peningkatan kunjungan wisatawan (Y) di Kota

\section{Uji Asumsi Klasik}

a. Uji Normalitas

Uji normalitas bertujuan untuk mengetahui normal tidaknya suatu distribusidalam sebuah penelitian. Pada penelitian ini uji normalitas menggunakan Kolmogrov-Smirnov dengan syarat nilai signifikan uji K$\mathrm{S}>0,05$. Uji normalitas pada penelitian dilakukan agar dapat melihat tersdistribusi dengan semestinya atau tidak, adapun tabulasinya. hasil uji normalitas Kolmogrov-Smirnov dapat dilihat bahwa nilai Sig. Pada bagian Asymp. Sig. (2-tailed) sebesar
Palopo dinyatakan reliabel karena memiliki nilai Cronbach Alpha $\geq$ 0,6

0,170. Dengan demikian dapat disimpulkan bahwa distribusi data yang diperoleh normal karena Asymp. Sig. (2-tailed)> 0,05 yaitu sebesar 0,170

\section{b. Uji Regresi Sederhana}

Analisis regersi sederhana bertujuan untuk mengerahui arah hubungan antara variabel independen dengan variabel dependen serta untuk mengetahui sebagaimana variabletersebut berpengaruh apakah variabel tersebut mengalami penurunan atau kenaikan. Adapun hasil analisis 


\section{Tabel 6 Hasil uji regresi linear sederhana}

Coefficients $^{\mathrm{a}}$

\begin{tabular}{|c|c|c|c|c|c|}
\hline & \multicolumn{2}{|c|}{$\begin{array}{c}\text { Unstandardized } \\
\text { Coefficients }\end{array}$} & $\begin{array}{c}\text { Standardized } \\
\text { Coefficients }\end{array}$ & & \\
\cline { 2 - 5 } Model & $\mathrm{B}$ & $\begin{array}{c}\text { Std. } \\
\text { Error }\end{array}$ & Beta & $\mathrm{T}$ & Sig. \\
\hline (Constant) & 6.778 & 1.960 & & 3.458 & .001 \\
Strategi Promosi & .660 & .087 & .609 & 7.605 & .000 \\
\hline
\end{tabular}

a. Dependent Variable: Peningkatan Kunjungan wisatawan

Sumber : Hasil Pengelolahan Data Primer 2020

Dari hasil pengujian regresi linear sederhana pada tabel 6 maka dapat dibentuk persamaan regresi $\mathrm{Y}=$ $6.778+0.660 \mathrm{X}$. Karena angka koefesien regresi bernilai positif $(+)$ maka dapat dikatakan bahwa strategi promosi berpengaruh positif (X) terhadap peningkatan kunjungan wisatawan (Y). Koefesien regresi sebesar 0,660 menyatakan bahwa setiap penambahan strategi promosi maka akan ada peningkatan sebesar 0,660 pada peningkatan kunjungan wisatawan.

\section{Uji Hipotesis (Uji T)}

Uji t dilaksanakan untuk melihat hal yang jelas dari variabel, dengan perolehan:

a. Menentukan Hipotesis Alternatif $\left(\mathrm{H}_{\mathrm{a}}\right)$ dan Hipotesis $\left(\mathrm{H}_{0}\right)$

$\mathrm{H}_{0}$ : Strategi promosi tidak berpengaruh positif terhadap peningkatan kunjungan wisatawan.

$\mathrm{H}_{\mathrm{a}}$ : Strategi promosi berpengaruh positif terhadap peningkatan kunjungan wisatawan

b. Menentukan Resiko Kesalahan

Taraf siginifikan atau $\alpha$ (alpha) yang digunakan dalam penelitian ini adalah 5\%(0,05).

c. Menghitung t statistik ( $\mathrm{t}$ hitung) dan ttabel

Nilai t hitung diperoleh dari output SPSS (lihat di tabel 4.9) yaitu 7.605. Kemudian $t$ tabel dicari pada tabel statistik pada signifikan 0,05 dengan $\mathrm{df}=\mathrm{n}-\mathrm{k}$ atau $100-2=98$, nilai $\mathrm{t}$ tabel didapat sebesar 1,660.

d. Menentukan Kriteria Uji t

$\mathrm{H}_{0}$ ditolak dan $\mathrm{Ha}$ diterima jika $t$ hitung $>\mathrm{t}$ tabel $\mathrm{H}_{0}$ diterima dan $\mathrm{Ha}$ ditolak jika thitung $\leq \mathrm{t}$ tabel

e. Membuat Kesimpulan

Berdasarkantabel 6 dapat dilihat bahwa $\mathrm{t}$ hitung untuk persepsi pada strategi promosi (X) sebesar 0,660 dan nilai signifikan sebesar0,000. Nilai $t$ hitung lebih besar dari $t$ tabel 1,660 dan nilai signifikasi lebih kecil dari 0,05. Dengan demikian maka $\mathrm{H}_{0}$ ditolak dan $\mathrm{H}_{\mathrm{a}}$ diterima. Artinya strategi promosi berpengaruh positif terhadap peningkatan kunjungan wisatawan di Kota Palopo 


\section{E. PEMBAHASAN}

\section{Strategi Promosi}

Hasil analisa deskriptif pada tabel 1 menunjukan bahwa indikatorindikator yang ada pada variabel strategi promosi memiliki kategori sangat baik. Nilai tertinggi terdapat pada pernyataan 3 yaitu pemerintah Kota Palopo menyampaikan pesan atau berita kepada masyarakat dengan skor 4,70 yang masuk dalam kategori sangat baik. Sedangkan nilai terendah terdapat pada pernyataan 5 yaitu pemerintah kota palopo melakukan penggunaan media baru informasi yang di komunikasikan ke masyarakat dengan menggunakan media internet masuk dalam kategori sangat baik dengan skor 4,33, dan untuk pernyataan 1, 2 dan 4 masuk juga dalam kategori sangat baik yaitu dimana pernyataan 1 melakukan publikasi yang dilakukan oleh wartawan lokal dan non lokal dengan skor 4,47, pernyataan 2 melakukan press releaceatau berita untuk surat kabar kepada media massa dengan skor 4,36. Dan untuk pernyataan 4 melakukan event/acara dalam proses penyebaran informasi kepada masyarakat dengan skor 4,30. Dan dapat disimpulkan bahwa secara keseluruhan strategi promosi untuk kebijakan pemerintah di Kota Palopo termasuk dalam kategori sangat baik dengan nilai total rata-rata adalah 4,50 .

\section{Peningkatan Kunjungan Wisatawan di Kota Palopo}

Hasil analisa deskriptif pada tabel 1 menunjukan bahwa indikatorindikator yang ada pada variabel strategi promosi memiliki kategori sangat baik dan cukup baik. Nilai rata-rata tertinggi terdapat pada pernyataan 4 fasilitas pelayanan dengan skor 4,71, dan nilai rata-rata yang palin rendah terdapat pada pernyataan 2 yaitu fasilitas transportsai dengan skor 3,33 cukup baik. Dan untuk pernyataan 1, 3 dan 5 masuk dalam kategori sangat baik, dimana pernyataan 1 yaitu mengetahui karasteristik dari wisatawan dari negara mana mereka datang dengan skor 4,44 . pernyataan 3 yaitu bagaimana daya tarik wisata apakah sudah memenuhi syarat dengan skor 4,50 dan pernyataan 5 yaitu diperlukan publikasi untuk promosi, kapan iklan dipasang, kemana leaflets/brosur disebarkan sehingga calon wisatawan mengetahui tiap paket wisata dan wisatawan cepat mengambil keputusan dengan skor 4,65. Dan dapat disimpulkan bahwa secara keseluruhan untuk peningkatan kunjungan wisatawan dalam kebijakan pemerintah di Kota Palopo termasuk dalam kategori sangat baik dengan nilai total rata-rata adalah 4,33 .

\section{Pengaruh Strategi Promosi Terhadap Peningkatan Kunjungan Wisatawan}

Penelitian ini bertujuan untuk mengetahui pengaruh strategi promosi terhadap peningkatan kunjungan wisatawan di Kota Palopo. Berdasarkan hasil pengujian hipotesis yang dilakukan, menunjukan bahwa strategi promosi berpengaruh positif terhadap peningkatan kunjungan wisatawan di Kota Palopo. Hal ini terbukti dengan thitung $(7,605)$ lebih besar dari $\mathrm{t}$ tabel $(1,660)$ dengan demikian $\mathrm{H}_{\mathrm{O}}$ ditolak dan $\mathrm{Ha}$ diterima. Hal ini dapat dilihat dari nilai koefesien regresi (beta) pada variabel strategi promosi (X) sebesar positif 
0,660 dan signifikan 0,000 lebih kecil dari 0,05 .

Bahwa strategi promosi berpengaruh positif terhadap peningkatan kunjungan wisatawan di Kota Palopo. Karena terdapat strategi promosi yang berupa News (pesan/berita) melalui media sosial, Event (acara) yaitu salah satunya PAF (Event Art Festifal) untuk kegiatan tahunan, panggung kreatif tiap bulannya, lomba foto, dan lomba film pendek. Atau kegiatan rutin yang selalu dilaksanankan oleh pemerintah sehingga semakin banyak promosi yang dilakukan maka semakin baik peningkatan kunjungan wisatawan yang ada di Kota Palopo.

Hasil pengkajian yang dilaksanakan Irmawati (2013) tentang "Pengaruh Promosi Terhadap Jumlah Wisatawan (Studi Kasus di gedung Perundingan Linggajati Kuningan)" Hasil penelitian menunjukan bahwa promosi berpengaruh terhadap jumlah wisatawan.dapat diterima

\section{F. KESIMPULAN}

Berdasarkan hasil pengujian hipotesis yang dilakukan, menunjukan bahwa strategi promosi berpengaruh positif terhadap peningkatan kunjungan wisatawan di Kota Palopo. Hal ini terbukti dengan $\mathrm{t}$ hitung $(7,605)$ lebih besar dari t tabel $(1,660)$ dengan demikian $\mathrm{H}_{\mathrm{O}}$ ditolak dan $\mathrm{H}_{\mathrm{a}}$ diterima. Hal ini dapat dilihat dari nilai koefesien regresi (beta) pada variabel strategi promosi $(\mathrm{X})$ sebesar positif 0,660 dan signifikan 0,000 lebih kecil dari 0,05. Bahwa strategi promosi berpengaruh positif terhadap peningkatan kunjungan wisatawan.

\section{DAFTAR PUSTAKA}

Akrom, Muhammad.2014. Analisis

Faktor-Faktor

Mempengaruhi yang

Wisatawan di Pantai Waleri,
Kabupaten Kendal (skripsi)

Semarang: Universitas

Diponegoro.

Andi Nur Azakiyah.2013. Strategi

Promosi Dinas Kebudayaan dan

Pariwisata dalam meningkatkan

kunjungan wisatawan di pantai

Tanjung Bira Kecamatan

Bontobahari Kabupaten

Bulukumba.

Agung Iskandar. 2012. Panduan Penelitian Tindakan Kelas Bagi Guru, Jakarta : Bestari Buana Murni.

Areks, E., \& Nadjib, M. (2015). Pengaruh penggunaan bauran promosi terhadap tingkat kunjungan wisatawan pada objek wisata alam di kabupaten Pangkajene dan kepulauan. KAREBA : Jurnal Ilmu Komunikasi, 4(4)Bambang Prasetyo, Lina Miftahul Jannah.2008.Metode Penelitian Kuantitatif: Teori dan Aplikasi. Ed-1-4,-PT Raja Gramindo Persada, Jakarta.

Dewi Megawati (2008). Analisis Efektifitas Promosi Terhadap Jumlah Pengunjung Taman Safari Indonesia. Jurnal.

Dhamar Ardha Yuasta.2012. Peran Dinas Priwisata Kebudayaan dan Pariwisata dalam Meningkatkan Kunjungan Wisatawan (Studi Pengembangan Ekonomi di KabupatenNganjuk).

Estu Handayani, Muhammad Dedi (2017), Pengaruh Promosi Wisata bahan dankualitas pelayanan terhadap peningkatan jumlah kunjungan wisatawan di pelabuhanmuncar.

Irmawati .2013. Pengruh Strategi Promosi Terhadap Jumlah Wisatawan (studi kasus di 
gedung perundingan linggarjati kuningan),Jurnal.

Lupiyoadi, R. 2013. Manajemen Pemasaran Jasa : Berbasis Kompetensi, Edisi 3. Jakarta : Salemba Empat.

Mayasari, Yuriska. Dkk. 2014. Penerapan Teknik Probing Promting dalam Pembelajaran Matematika Siswa Kelas VIII MTSN Lubuk Buaya Padang. Jurnal Pendidikan Matematika IAIN Tulung Agung.

Nova, Firsan. 2011. Crisis Public Relations Bagaimana PR Menangani Krisis Perusahaan, Jakarta : Raja Grafindo Persada.

Pendit, S. Nyoman 1999. Ilmu Pariwisata Perdana, Jakarta :

Pradya Paramita.Rizki Munanda, Syamsul Amar (2018). Pengaruh Kunjungan Wisatawan Mancanegar, Rata-Rata Pengeluaran dan Tingkat Hunian Hotel Terhadap Pendapatan Indonesia pada Sektor Pariwisata,

Sarjono, Haryadi, dan Julianta, Winda. 2013. SPSS VS LISREL: Sebuah Pengantar, Aplikasi untuk Riset, Penerbit Salemba Empat. Jakarta.

Suryadana, M. Liga dan Octavia Vanny. 2015. Pengantar PemasaranPariwisata. Bandung : Alfabet.

Sugiyono.2004. Metode Penelitian. Bandung : Alfabet.

Sugiyono.2012. Metode Penelitian Kuantitatif Kualitatif dan $R \& D$. Bandung : Alfabet.

Sugiyono.2013. Metode Penelitian Pendidikan Pendekatan Kuantitatif Kualitatif dan $R \& D$. Bandung : Alfabet.

Tjiptono.2008. Strategi Pemasaran,
Edisi 3, Andi : Yogyakarta.

Widyasti, F. R.2013. Skripsi Strategi : Promosi Wisata pada Dinas Kebudayaan dan Pariwisata, Universitas Negeri Yogyakarta.

Yanti. Dkk. 2012 "Pengaruh Konpensasi, motivasi kerja, lingkungan kerja dan disiplin kerja terhadap kinerja karyawan pada CV Koperasi Puri Kencana Taxi Semarang”. Jurnal. Semarang. Universitas Pandanaran.

Yuliana.2010. Strategi Promosi Dinas Pariwisata dalam meningkatkan wisatawan di warung ApungJimbung.

Indriastuty, N. (2020). Pengaruh bauran promosi terhadap minat pengunjung Wisata budaya pesta adat Erau. Jurnal Manajemen Komunikasi, 4(2), 61-80.

Lesmana, I. S., Bahits, A., \& Tabrani, M. B. (2020). Strategi Promosi Pengelolaan Wisata Pantai Untuk Meningkatkan Kunjungan Wisatawan Pasca Tsunami Selat Sunda Di Kabupaten Pandeglang. Jurnal Manajemen STIE Muhammadiyah Palopo, 6(2), 61 -65. 